\title{
O Programa PIBID como ação formativa e incentivo aos futuros professores de matemática para exercício da docência no ensino público*
}

\author{
Marcelo Furlin** \\ Silvana Pucetti***
}

\section{Resumo}

Com o objetivo de melhor qualificar os futuros professores em processo de formação inicial, o PIBID, instituído em 2012, estabeleceu a parceria entre o Ensino Superior, a Educação Básica da rede pública de ensino,

* O presente artigo deriva de um extenso trabalho de pesquisa apresentado ao Programa de Pós-graduação em Educação da Universidade Metodista de São Paulo, em nível de doutorado, sob título "A formação do professor de Matemática em interface com o Programa Institucional de Bolsas de Iniciação à Docência (PIBID): as representações de licenciandos e supervisores", elaborado sob a orientação da Profa. Dra. Norinês Panicacci Bahia, e que foi defendido e aprovado com louvor em 30.11.16. A tese original apresenta outras pesquisas de natureza qualitativa e de aprofundamento, contando, inclusive, com entrevistas e análise das principais categorias evidenciadas no discurso dos sujeitos da pesquisa e que, posteriormente, serão divulgadas como artigos específicos. A tese completa encontra-se disponibilizada para consulta nos seguintes sites: <http://tede.metodista.br/jspui/bitstream/ tede/1622/2/Silvana\%20Pucetti.pdf > e http://tede.metodista.br/jspui/bitstream/tede/1622/2/Silvana \%20Pucetti.pdf.

** Doutor em Letras pela Universidade de São Paulo. Coordenador do Programa de Pós-Graduação em Educação da Universidade Metodista de São Paulo - email:marcelo.furlin@metodista.br

*** Professora Doutora do corpo docente da Universidade Metodista de São Paulo - Escola de Comunicação, Educação e Humanidades - e-mail: silvana. pucetti@metodista.br 
profissionais experientes e licenciandos, para vincular a teoria e a prática como elementos essenciais para o fornecimento de uma Educação de qualidade. $O$ presente trabalho, por meio de uma pesquisa de campo quali-quantitativa com 33 licenciandos de um curso de Matemática de uma IES de São Bernardo do Campo, investigou a opinião dos sujeitos em relação a questões fundamentais da Educação e, principalmente, sobre a intenção deste público de permanecer na rede pública de ensino, depois da formatura. Constatou que a grande maioria dos entrevistados manifesta esta vontade, embora em caráter temporário, devido à maior atratividade do trabalho na rede particular de ensino.

Palavras-chaves: PIBID. Formação de Professores. Educação Básica. Subprojeto de Matemática.

\title{
The PIBID Program as a training and incentive action for the future teachers of mathematics for the exercise of teaching in public education
}

\begin{abstract}
Aiming at better qualification for future teachers in their process of initial training, in 2012, the so-called PIBID established a partnership between Higher Education and Basic Education of the public-school system, experienced professionals and graduates, in order to link theory and practice as essential elements for quality education. This study has investigated the opinion of 33 graduates of a Mathematics course in the IES Program from São Bernardo do Campo through a qualitative-quantitative field research in which the individuals were questioned about fundamental questions of education and, mainly, the intention of this public to remain in the public-school system after graduation. The results have shown that the vast majority of the individuals expressed this willingness, although on a temporary basis, due to the greater attractiveness of work in the private education system.
\end{abstract}

Keywords: PIBID. Teacher training. Basic education. Subproject of Mathematics. 


\section{El Programa PIBID como acción formativa e incentivo a los futuros profesores de matemática para ejercicio de la docencia en la enseñanza pública}

\section{Resumen}

Con el objetivo de mejor calificar a los futuros profesores en proceso de formación inicial, el PIBID, instituido en 2012, estableció la asociación entre la Enseñanza Superior, la Educación Básica de la red pública de enseñanza, profesionales experimentados y licenciandos, para vincular la teoría y la investigación práctica como elementos esenciales para el suministro de una educación de calidad. El presente trabajo, por medio de una investigación de campo cualicuantitativa con 33 licenciandos de un curso de Matemáticas de una IES de São Bernardo do Campo, investigó la opinión de los sujetos en relación a cuestiones fundamentales de la Educación y, principalmente, sobre la intención de este público de permanecer en la red pública de enseñanza, después de la graduación. Constató que la gran mayoría de los entrevistados manifiesta esta voluntad, aunque en carácter temporal, debido a la mayor atracción del trabajo en la red particular de enseñanza.

Palabras clave: PIBID. Formación de profesores. Educación básica. Subproyecto de Matemáticas.

\section{Introdução}

Em vista do objetivo do Programa Institucional de Bolsas de Iniciação à Docência (PIBID) de estimular e qualificar a docência para a rede pública de ensino, o presente trabalho apresenta o programa e a pesquisa desenvolvida com bolsistas participantes do PIBID no Subprojeto "Formas Diferenciadas para o Ensino de Matemática", desenvolvido em parceria com a IES de origem dos licenciandos e duas escolas públicas da região de São Bernardo do Campo (SP), por meio da qual foram investigadas importantes questões relativas à formação e o exercício docente e, em especial, averiguada a intenção destes futuros professores em lecionar e permanecer na rede pública de ensino, depois de formados.

Para o embasamento teórico do tema e apresentação da pesquisa foram selecionados os seguintes eixos de abordagem: 
Os aspectos da evolução histórica da Educação, do ensino e da formação de professores de Matemática no Brasil.

O PIBID e o Subprojeto "Formas Diferenciadas para o Ensino de Matemática".

A pesquisa de campo quali-quantitativa ${ }^{1}$ realizada com 33 licenciandos do curso de Licenciatura em Matemática, de uma IES de São Bernardo do Campo (SP), com atuação em duas escolas públicas da região, por meio do PIBID e do Subprojeto "Formas Diferenciadas para o Ensino de Matemática”.

\section{Aspectos da educação, do ensino e da formação de professores de matemática no Brasil}

Durante séculos, o modelo da Educação brasileira desenvolveu-se com base nos padrões de ensino originários de Portugal, à época da colonização, e, posteriormente, da França, de outros países da Europa e dos Estados Unidos - nações consideradas como berços da cultura e centros provedores da Ciência. Como exemplo, nas décadas de 1930 e 1940, ainda prevalecia no Brasil a educação fundamentada no positivismo francês (MIGUEL; MIORIM, 2004; OLIVEIRA; CATANI; SILVA-JÚNIOR, 2010).

A história do país revela um longo e árduo caminho percorrido por educadores e pela sociedade para criar uma Educação com uma identidade nacional e para a efetivação de um sistema de ensino público com livre acesso para a população em geral. $\mathrm{O}$ primeiro movimento neste sentido data de 1824, quando a Constituição Política do Império do Brasil instituiu a Educação como um direito de todos. Apesar do valor da iniciativa imperial, no entanto, observou-se a lei como "letra morta", pois este direito somente foi efetivamente assegurado pelo Poder Público a partir da Lei de Diretrizes e Bases da Educação Nacional, sob número LDBEN-4.024, em 1961, ou seja, 137 anos depois da Constituição do Império. Tal morosidade espelha a forma como a Educação no Brasil se conso-

A natureza quali-quantitativa da pesquisa deve-se à realização de entrevistas de aprofundamento com seis licenciandos, selecionados no conjunto dos 33 licenciandos pesquisados. 
lidou, evoluiu e delineou a sua própria identidade: a passos lentos (BRASIL, 1824; BRASIL, 1961).

$\mathrm{Na}$ atualidade, o direito à Educação obrigatória e gratuita é garantido pela Constituição da República Federativa do Brasil de 1988 e pela Lei de Diretrizes e Bases da Educação Nacional LDBEN-9.394/1996 (BRASIL, 1988; BRASIL, 1996).

Os modelos importados igualmente influenciaram o ensino da Matemática no país, pois, até o início do século XX, apresentava um caráter tecnicista ou conteudista, semelhante ao sistema europeu, e era restrito aos estudos desenvolvidos pelo Instituto Militar de Engenharia do Rio de Janeiro (CURI, 2000).

O Curso de Licenciatura em Matemática, inicialmente, contava com professores das Academias Militares e da Escola Politécnica, apresentavam conhecimentos específicos e solidificados em uma vertente essencialmente técnica, sem formação didática, caracterizando o exercício de uma docência pautada na reprodução de conhecimentos e sem um compromisso firmado com a aprendizagem e a real assimilação do saber (CURI, 2000).

Em 1934, foram criados os primeiros cursos de formação de professores de Matemática no Brasil, ministrados pela Faculdade de Filosofia da Universidade de São Paulo (USP), contando com as disciplinas de Análise Matemática, Geometria Analítica e Projetiva, Cálculo Vetorial, Física, Álgebra, Topologia e Análise Funcional (MIGUEL; MIORIM, 2004; OLIVEIRA; CATANI; SILVA-JÚNIOR, 2010).

Apesar da concepção da Matemática vigente à época, fortemente influenciada pelas tendências dos Estados Unidos e Europa, tem início a discussão e realização de vários congressos relativos ao quadro educacional da disciplina e à introdução da Matemática Moderna. No entanto, somente por ocasião do III Congresso de Ensino de Matemática no Curso Secundário, realizado no Rio de Janeiro em 1959, que algumas decisões foram efetivadas, como, por exemplo, a instituição dos cursos de aperfeiçoamento para professores com a intenção de introduzir a Matemática Moderna, as teorias dos conjuntos e a álgebra nas Faculdades de Filosofia. 
Não obstante os inúmeros debates e experiências realizadas, apenas a partir de 1960 que o ensino da Matemática Moderna ganha destaque no país, quando são trabalhadas as estruturas da lógica matemática, da teoria dos conjuntos e da simbologia específica da linguagem Matemática (PIRES, 2000).

A ideia de renovação por parte de alguns professores apresentou relevante contribuição, inclusive, no sentido de valorizar o ensino da Matemática, principalmente na modalidade do ensino secundário. Em São Paulo, por exemplo, o marco para a instituição do movimento da Matemática Moderna foi a criação do "Grupo de Estudo do Ensino da Matemática (GEEM)", em 1961, sob a liderança de Oswaldo Sangiorgi. Este movimento encontrou ressonância e posterior reprodução em Porto Alegre e no Rio de Janeiro, respectivamente em 1970 e 1976. O primeiro curso de aperfeiçoamento em Matemática foi igualmente concebido e organizado por Sangiorgi, via Instituto Mackenzie (FIORENTINI, 1995).

A ênfase na preparação didática dos educadores surgiu com a promulgação da LDBEN-4.024/1961 e do Parecer CFE n. 292/1962, do Conselho Federal de Educação (CFE), diplomas legais que estabeleceram um novo currículo para o Curso de Licenciatura em Matemática com disciplinas curriculares nos três primeiros anos do curso, e disciplinas pedagógicas no último ano (BRASIL, 1961; BRASIL, 1962).

$\mathrm{Na}$ efervescência das múltiplas mudanças ocorridas nas décadas de 1960 e 1970, que impactaram o cenário político, econômico e sociocultural, o sistema de ensino que, em princípio, atendia apenas uma pequena fração da população brasileira, mesmo havendo a determinação legal da "Educação para todos", passou a atender uma grande parcela desta população. Outras alterações relevantes ocorridas no período foram constituídas pelo aumento do tempo de permanência dos alunos na escola e pela sua heterogeneidade, pois as salas de aula passaram a abrigar alunos de diferentes estratos socioeconômicos. Entretanto, as condições e recursos para o ensino não acompanharam as novas demandas, culminando 
com grandes dificuldades decorrentes (FERREIRA-JÚNIOR; BITTAR, 2006; SILVA, 2013).

Na década de 1980, um novo olhar projeta-se para o ensino da disciplina: a Educação Matemática, que destaca a importância do papel dos professores em sala de aula e de sua formação profissional. As diferenças sociais, culturais e educacionais passam a receber maior atenção no momento de estruturar o currículo e efetiva-se a preocupação com a elaboração de um currículo que possa atender a todos os alunos, independente de suas diferenças.

Inúmeras reflexões pautaram as discussões realizadas ainda na década de 1980, tais como: a posição entre a "velha" e a "moderna" Matemática; entre "construção de estruturas" e "solução de problemas"; entre "Matemática pura" e "Matemática aplicada"; e entre as técnicas tradicionais e novas técnicas de ensino. Com isso, o "Movimento da Matemática Moderna" gradativamente cede lugar ao movimento da "Educação Matemática", e importantes educadores matemáticos despontam com propostas inovadoras e com formas e metodologias de ensino diferentes. Entre os principais expoentes, destaca-se Ubiratan D’Ambrósio, que propõe a “Etnomatemática", um ensino mais "aclimatado" à realidade nacional e voltado para o dia a dia do aluno, para a resolução de problemas e estabelecimento de conexões matemáticas com outras disciplinas e conhecimentos, de forma direcionada às experiências e vivências concretas dos alunos.

Ainda nessa época, chegam ao Brasil as ideias do educador e pesquisador Seymour Papert, que propõe o uso do computador para colocar o aluno em contato com as ideias da Ciência, da Matemática e da criação de modelos. Papert traz para o cenário do ensino a "Filosofia LOGO", uma linguagem interpretativa aplicada de forma interativa para que o aluno possa desenvolver "ideias" e construir figuras. Tais experimentos apresentaram-se como uma crítica e um contraponto à tradicional Matemática escolar.

Na sequência, já no século XXI, com o movimento da Educação Matemática, uma nova metodologia ganhou destaque: a "Mate- 
mática estudada através dos jogos e de materiais concretos", que simula a realidade, serve de motivação para o aluno pensar, representar o pensamento e transpor a experiência para a linguagem simbólica.

Como resultado da releitura e evolução da matéria, atualmente, os currículos de Licenciatura em Matemática incluem estudos na área da Educação Matemática, da Informática Educativa e demais tecnologias, com o objetivo de promover diferentes formas de ensinar e aprender, de modelar o comportamento e o amadurecimento intelectual e afetivo, tanto por parte dos alunos, como também dos educadores.

As novas dinâmicas e demandas de ensino, no Brasil, lançaram, e continuamente lançam, novos desafios aos professores, que necessitam ressignificar a sua função, se reinventar todos os dias, posicionarem-se diante da profissão como "eternos aprendizes" e "profissionais em contínua formação", de modo a se capacitarem para ensinar em um mundo densamente tecnológico, globalizado e em constante transformação.

No entanto, na contramão das novas exigências postas no âmbito da Educação, observa-se, ainda e há muito tempo, sérios problemas, dificuldades e deficiências a serem enfrentadas pelos educadores, no que se refere às condições de trabalho, aos recursos disponíveis nas escolas da rede pública de ensino e, principalmente, relativos aos aspectos de valorização do seu trabalho (baixa remuneração e reduzido prestígio social), pois aos professores, não raras vezes, é atribuída a total responsabilidade pelos padrões da Educação e pelo desempenho dos alunos, como se estes fossem os únicos responsáveis pela qualidade da Educação nacional - uma concepção equivocada, cotidianamente evidenciada pelas mídias, principalmente a televisiva, de forma associada às intenções governamentais de otimização da formação dos docentes, que tem resultado em consequências e prejuízos à sociedade.

Como uma forma de enfrentamento da questão, o Governo tem estabelecido políticas públicas para a Educação nas últimas décadas, dentre as quais o PIBID se destaca no sentido de incentivar 
a docência, de valorizar o trabalho dos professores em exercício e dos futuros professores (licenciandos bolsistas do programa), e direciona ações para a melhoria do processo de ensino-aprendizagem - tema a seguir abordado.

\section{O PIBID e o subprojeto "formas diferenciadas para o ensino de matemática"}

O PIBID foi instituído pelo Decreto n. 7.219/2010 e pelas Leis de n. LDBEN-9.394/1996 e 12.796/2013, como um dos programas da Coordenação de Aperfeiçoamento de Pessoal de Nível Superior (CAPES), com o objetivo de promover e incentivar a iniciação à docência, bem como aperfeiçoar a formação docente em nível superior e a Educação Básica nacional (BRASIL, 1996; BRASIL, 2010; BRASIL, 2013).

O PIBID divide-se em Subprojetos específicos por área de conhecimento/disciplina e envolve, além de uma ação conjugada, relações de parceria entre instituições de ensino superior (IES), escolas públicas municipais (EMEF) e/ou estaduais (EEEF), os professores de ambas as instituições de ensino e os licenciandos admitidos no programa. Trata-se de uma política governamental focada em romper paradigmas já institucionalizados e cristalizados ao longo das décadas, e que busca eliminar o distanciamento ainda prevalente entre os níveis de ensino. Ou seja, o programa busca estabelecer uma estreita relação entre a teoria e a prática no exercício da docência, ao promover a articulação do Ensino Superior com a Educação Básica e intensificar a formação inicial dos futuros professores, por meio de ações acadêmicas propostas pela universidade e experiências reais vivenciadas na unidade escolar (BRASIL, 2015).

O PIBID oportuniza a inserção dos licenciados no cotidiano escolar, sob o acompanhamento efetivo de professores mais experientes da escola pública parceira, de forma a qualificá-los para a melhoria do processo de ensino-aprendizagem, ainda no decorrer do seu percurso formativo. Com isso, o programa estabelece uma integração e intercâmbio de comunicação, de conhecimentos e ex- 
periências entre os profissionais em exercício, o corpo acadêmico e os licenciandos que, em um futuro muito próximo, serão inseridos no âmbito da Educação, seja ela púbica ou particular, e no mercado de trabalho (BRASIL, 2015).

Por apresentar-se como um programa de incentivo à docência, com vistas a contribuir para a transformação da Educação, o PIBID abre espaço para uma nova visão e prática do ensino, para a aplicação de novas e diferenciadas metodologias e didáticas e, no caso da Matemática, para a utilização de materiais concretos e jogos - um recurso lúdico a serviço de uma Educação com melhor qualidade, mais reflexiva, atrativa e prazerosa para os alunos.

Por meio do Subprojeto de Matemática, intitulado como "Formas Diferenciadas para o Ensino de Matemática", o programa reúne como metas principais: facilitar a aprendizagem dos alunos da rede pública; desmistificar a aura de complexidade que envolve o estudo da disciplina; romper as barreiras, o medo e o bloqueio que tantos alunos manifestam em relação à matéria e que dificultam a compreensão de seus conceitos e conteúdos (BRASIL, 2015).

Sobretudo, o Programa e o Subprojeto de Matemática operam no sentido de estabelecer e consolidar a ideia da aplicação prática da disciplina na vida cotidiana do estudante, em qualquer espaço de tempo, geográfico ou cultural, pois o estudo da Matemática não deve ser visto apenas como teórico e obrigatório, mas como uma necessidade da vida humana em sociedade, em todos os seus âmbitos e setores e, principalmente, como um saber atemporal e essencial para a compreensão do mundo e do universo.

\section{Pesquisa de campo realizada com licenciandos bolsistas do PIBID}

Este capítulo apresenta a pesquisa de campo quali-quantitativa realizada no período de 2014 e 2015 com 33 licenciandos de uma IES de São Bernardo do Campo (SP), participantes como bolsistas do Subprojeto "Formas Diferenciadas para o Ensino de 
Matemática”, do Programa PIBID, em duas escolas públicas da região, durante o seu percurso formativo.

O desenvolvimento da pesquisa obedeceu aos princípios metodológicos definidos por Minayo e Sanchez (1993), Richardson (1999) e Yin (2010), bem como aos principais protocolos estabelecidos para as pesquisas em nível acadêmico e científico, no que se refere à:

Elaboração e aplicação dos Instrumentos de Pesquisa constituídos por Termo de Consentimento Livre e Esclarecido e Declaração de Responsabilidade dos Pesquisadores, que esclarecem ao entrevistado o propósito e a lisura dos procedimentos da pesquisa e a conduta ética dos pesquisadores em relação às informações fornecidas.

Elaboração e aplicação dos Instrumentos de Coleta de Dados constituídos por Questionário para Perfil Sociodemográfico do Entrevistado (sistema fechado) e Questionário com nove Perguntas Relativas à Educação (sistema aberto).

Como procedimentos aplicados à consecução da pesquisa, primeiramente os 33 licenciandos responderam um questionário com as questões para composição do perfil e, posteriormente, responderam o questionário com as nove perguntas relativas à Educação. Deste conjunto de sujeitos foram selecionados seis licenciandos para as entrevistas de aprofundamento e ampliação das respostas inicialmente fornecidas. A partir dos dados coletados, foi organizada a tabulação e o agrupamento das respostas que deram origem às sínteses apresentadas nos Quadro 1, 2 e 3, seguidos da análise e discussão dos resultados.

\subsection{O PIBID na instituição de ensino superior e escolas públicas parceiras pesquisadas}

O PIBID foi implantado em 2012 na instituição de ensino superior pesquisada (IES) e manteve sete subprojetos nos cursos de licenciaturas presenciais e EAD, no período de 2012 a 2016, nas áreas de Ciências Biológicas, Ciências Sociais, Educação Física, Fi- 
losofia, Matemática e Pedagogia. Tais subprojetos foram desenvolvidos em parceria com 21 escolas públicas municipais e estaduais das Secretarias de Educação da região, contando com um quadro de 259 bolsistas, composto pelos seguintes cargos: coordenador institucional (1), coordenador de gestão e processos educacionais (1), coordenadores de áreas de subprojetos (13), supervisores/professores das escolas públicas (29) e licenciandos (215).

No escopo das atividades desenvolvidas destacaram-se as reuniões gerais com todos os bolsistas, entre os coordenadores de áreas e os bolsistas de cada subprojeto e entre os coordenadores institucionais e os representantes das Secretarias de Educação parceiras; além de ações formativas, participação em eventos da área, produção e publicação de livros e artigos, promoção de encontros específicos sobre o PIBID, confecção/elaboração de materiais, observações do cotidiano escolar, intervenções supervisionadas em salas de aulas, elaboração de relatórios, entre outras.

Especificamente, o Subprojeto "Formas Diferenciadas para o Ensino de Matemática”, foi realizado em seis escolas públicas parceiras da região do ABCD e, no período delimitado, ofereceram 40 bolsas de iniciação à docência para os licenciandos do curso de Matemática; oito bolsas de supervisão para os professores das escolas públicas parceiras e duas bolsas de coordenação de área para os professores da IES, os quais coordenam o subprojeto.

Para a viabilização da pesquisa, haja vista a grande população envolvida no Projeto PIBID e Subprojeto Matemática, foram selecionadas duas escolas públicas parceiras identificadas como "EESP" e "EELG" como lócus e 33 licenciandos bolsistas como sujeitos da pesquisa. O Projeto PIBID foi implantado simultaneamente nas duas escolas em 2012 e, portanto, apresentam o mesmo tempo de maturação. Outros dados relevantes foram destacados no Quadro 1, de forma a expressar o universo da pesquisa. 
Quadro 1 - Dados das duas escolas estaduais parceiras do Subprojeto Matemática PIBID, da IES investigada.

\begin{tabular}{|c|c|c|}
\hline Referências & Escola 1 & Escola 2 \\
\hline Escola [sigla] & EESP & EELG \\
\hline $\begin{array}{l}\text { Localização (Bairro, } \\
\text { Cidade e Estado) }\end{array}$ & $\begin{array}{l}\text { Vila São Pedro } \\
\text { São Bernardo do } \\
\text { Campo (SP) }\end{array}$ & $\begin{array}{c}\text { Subdistrito de Rudge } \\
\text { Ramos } \\
\text { São Bernardo do } \\
\text { Campo (SP) }\end{array}$ \\
\hline Quantidade de Alunos & 1.701 & 386 \\
\hline $\begin{array}{l}\text { Quantidade de } \\
\text { Professores }\end{array}$ & 63 & 21 \\
\hline $\begin{array}{ll}\text { Quantidade } & \text { de } \\
\text { Professores } & \text { de } \\
\text { Matemática } & \\
\end{array}$ & 11 & 4 \\
\hline Quantidade de Turnos & 3 & 1 Período Integral \\
\hline Quantidade de Turmas & 50 & 9 \\
\hline Níveis de Ensino & $\begin{array}{l}\text { Ensino } \\
\text { Fundamental II e } \\
\text { Ensino Médio } \\
\end{array}$ & Ensino Fundamental II \\
\hline $\begin{array}{l}\text { Início da Implantação } \\
\text { do PIBID }\end{array}$ & 2012 & 2012 \\
\hline
\end{tabular}

Fonte: Os Autores (2016).

Como pode ser observado no Quadro 1, as duas escolas, identificadas pelas siglas "Escola 1 - EESP" e "Escola 2 - EELG", localizam-se no município de São Bernardo do Campo (SP): a "Escola 1 - EESP" situa-se na periferia, mas ainda próxima ao centro do munícipio de São Bernardo do Campo (SP), enquanto a "Escola 2 - EELG" situa-se em um subdistrito da cidade, considerado como um bairro nobre. Apresentam dados bastante diferenciados, sob todos os aspectos, pois a "Escola 1 - EESP" é de ensino regular, enquanto que a "Escola 2 - EELG" é de período integral, o que explica a diferença dos números de alunos, professores e turmas. 


\subsection{O perfil dos licenciandos bolsistas do PIBID pes- quisados}

A partir de informações fornecidas pelos sujeitos da pesquisa foi traçado o perfil sociodemográfico de cada licenciando, conforme dados organizados no Quadro 2.

Os dados que compõem o perfil evidenciam que o grupo é formado predominantemente por sujeitos em idade adulta, visto que 26 licenciandos situam-se na faixa etária de 21 a 52 anos, principalmente entre 21 a 40 anos (23 licenciandos). A idade mínima é de 18 anos e a máxima de 52 anos. A maioria dos pesquisados é do gênero masculino (18), estado civil solteiro (19), 8 licenciandos possuem filhos e, sob o aspecto econômico, a remuneração da maioria é concentrada nas faixas "menor que $\mathrm{R} \$ 1.000,00$ " (11) ou “maior que $\mathrm{R} \$ 2.000,00 ”$ (8).

No que se refere à vida profissional e de dedicação de horas semanais ao exercício da docência, verifica-se que não há um padrão ou referência estabelecida, devido às diferenças existentes entre os números coletados, pois, no cômputo geral, 12 entrevistados não exercem a docência, 5 dedicam de 1 a 20 horas, 7 dedicam de 21 a 40 horas, 2 dedicam de 41 a 60 horas, 1 licenciando dedica de 61 a 80 horas semanais à docência e 6 licenciandos não responderam a questão. Como contraponto, 12 licenciandos realizam outras atividades profissionais remuneradas e 21 alegam não exercerem qualquer outra atividade.

A grande maioria (31) não participa de nenhum outro programa do Governo, além do PIBID, que reúne os seguintes números: 16 participam do programa entre 1 a 2 anos, 7 menos de 1 ano e 4 entre 2 a 4 anos.

4.3 Respostas dos licenciandos às questões relacionadas à educação e opção pessoal pela docência no ensino público depois de formados

A partir das respostas fornecidas pelos 33 licenciandos às questões sobre a Educação e opção pessoal pela docência no en- 


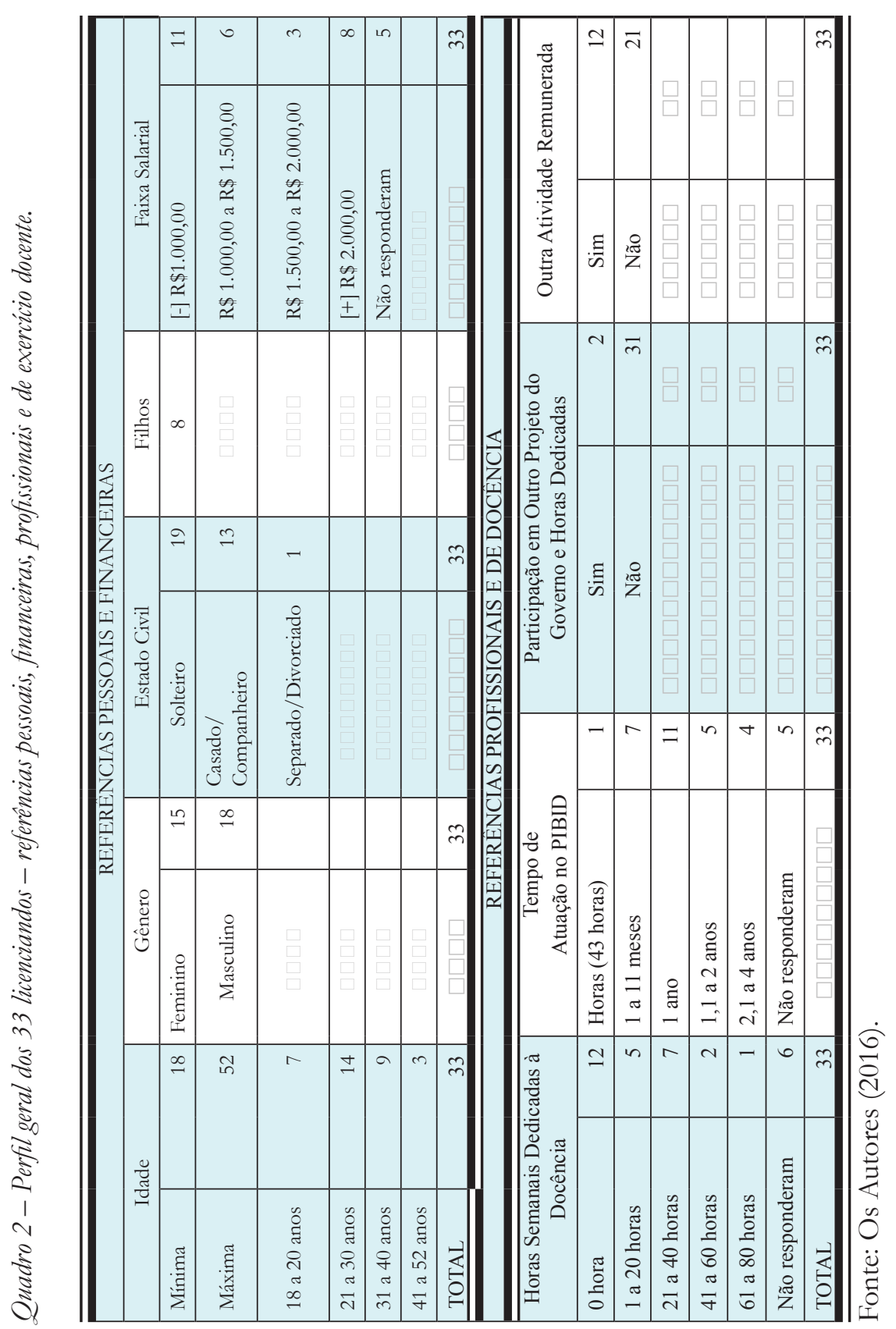

EDUCAÇÃO \& LINGUAGEM • v. 20 • N. 1 • 5-27 • JAN.-JUN. 2017 
sino público, depois de formados, como também considerando as respostas ampliadas por 6 licenciandos em entrevista de aprofundamento, organizamos uma síntese de cada questão com as palavraschave das respostas, conforme Quadro 3, que são a seguir analisadas sob a luz de referenciais teóricos pertinentes.

Quadro 3 - Sintese das respostas dos licenciandos às questões relativas à Educação e sua opção pela docência no ensino público depois de formados.

\begin{tabular}{|c|c|c|c|}
\hline \multirow{2}{*}{\multicolumn{2}{|c|}{$\begin{array}{l}\text { QUESTÕES } \\
\%\end{array}$}} & \multicolumn{2}{|c|}{ PERCENTUAL E SINTESE DAS RESPOSTAS } \\
\hline & & $\begin{array}{c}\text { SÍNTESE } \\
\text { DAS } \\
\text { RESPOSTAS }\end{array}$ & \\
\hline$\square$ & $\begin{array}{l}\text { A participação no PIBID } \\
\text { é uma medida positiva } \\
\text { no processo de formação } \\
\text { inicial do professor de } \\
\text { Matemática? }\end{array}$ & $100 \%$ & $\begin{array}{l}\text { Consideram a sua participação } \\
\text { no PIBID como positiva, devido } \\
\text { aos exemplos de professores mais } \\
\text { experientes, vivência em sala de } \\
\text { aula, contato com a realidade escolar } \\
\text { e experiência prévia ao exercício } \\
\text { profissional. }\end{array}$ \\
\hline$\square$ & $\begin{array}{l}\text { As diferentes ações } \\
\text { metodológicas utilizadas } \\
\text { pelos professores de } \\
\text { Matemática das escolas } \\
\text { parceiras, as quais } \\
\text { observadas através do } \\
\text { PIBID, agregam valor } \\
\text { à formação inicial do } \\
\text { professor? }\end{array}$ & $100 \%$ & $\begin{array}{l}\text { Consideram que as ações } \\
\text { metodológicas agregam valor à } \\
\text { formação inicial de professor, à } \\
\text { medida que contribui e ajuda a } \\
\text { identificar melhores técnicas e } \\
\text { didáticas, bem como possibilita a } \\
\text { observação de diversas condutas } \\
\text { adotadas pelos professores, formas de } \\
\text { administrar o trabalho em sala de aula } \\
\text { e as questões relativas aos alunos. }\end{array}$ \\
\hline$\square$ & $\begin{array}{l}\text { A proposta do PIBID } \\
\text { efetivamente permite aos } \\
\text { bolsistas vivenciarem a } \\
\text { realidade escolar desde o } \\
\text { início do curso? }\end{array}$ & $99 \%$ & $\begin{array}{l}\text { Consideram que o PIBID oferece } \\
\text { ao licenciando vivenciar a realidade } \\
\text { escolar desde o início do curso. }\end{array}$ \\
\hline$\square$ & $\begin{array}{l}\text { Através da sua inserção no } \\
\text { cotidiano escolar por meio } \\
\text { do PIBID, você observa } \\
\text { ações que integram a } \\
\text { universidade e a escola? }\end{array}$ & $93 \%$ & $\begin{array}{l}\text { Consideram que as ações do PIBID } \\
\text { integram a universidade e a escola. }\end{array}$ \\
\hline
\end{tabular}




\begin{tabular}{|c|c|c|c|}
\hline \multirow{2}{*}{\multicolumn{2}{|c|}{$\begin{array}{c}\text { QUESTÕES } \\
\%\end{array}$}} & \multicolumn{2}{|c|}{ PERCENTUAL E SINTESE DAS RESPOSTAS } \\
\hline & & $\begin{array}{l}\text { SÍNTESE } \\
\text { DAS } \\
\text { RESPOSTAS }\end{array}$ & \\
\hline$\square$ & $\begin{array}{l}\text { As ações que você } \\
\text { vivenciou nas reuniões } \\
\text { com as Coordenadoras do } \\
\text { PIBID contribuíram para a } \\
\text { sua formação profissional } \\
\text { e atuação no ambiente } \\
\text { escolar? }\end{array}$ & $100 \%$ & $\begin{array}{l}\text { Consideram que as ações vivenciadas } \\
\text { nas reuniões com as Coordenadoras } \\
\text { do PIBID contribuem para a sua } \\
\text { formação profissional e atuação no } \\
\text { ambiente escolar. }\end{array}$ \\
\hline$\square$ & $\begin{array}{l}\text { As ações que você } \\
\text { vivenciou nas reuniões } \\
\text { com as Supervisoras do } \\
\text { PIBID contribuíram para a } \\
\text { sua formação profissional } \\
\text { e atuação no ambiente } \\
\text { escolar? }\end{array}$ & $93 \%$ & $\begin{array}{l}\text { Consideram que as ações vivenciadas } \\
\text { nas reuniões com as Supervisoras } \\
\text { do PIBID contribuem para a sua } \\
\text { formação profissional e atuação no } \\
\text { ambiente escolar. }\end{array}$ \\
\hline$\square$ & $\begin{array}{l}\text { Você considera que o } \\
\text { PIBID tem contribuído } \\
\text { para a melhoria da } \\
\text { qualidade do ensino nas } \\
\text { escolas? }\end{array}$ & $90 \%$ & $\begin{array}{l}\text { Consideram que o PIBID tem } \\
\text { contribuído para a melhoria da } \\
\text { qualidade do ensino nas escolas. }\end{array}$ \\
\hline$\square$ & $\begin{array}{l}\text { Você avalia a sua atuação/ } \\
\text { participação no PIBID } \\
\text { como uma experiência } \\
\text { positiva para a sua vida } \\
\text { acadêmica e profissional? }\end{array}$ & $100 \%$ & $\begin{array}{l}\text { Avaliam a sua atuação/participação } \\
\text { no PIBID como uma experiência } \\
\text { positiva para a sua vida acadêmica e } \\
\text { profissional. }\end{array}$ \\
\hline$\square$ & $\begin{array}{l}\text { Você acredita que irá } \\
\text { optar pela docência na } \\
\text { escola pública, depois de } \\
\text { formado? }\end{array}$ & $81 \%$ & $\begin{array}{l}\text { Acreditam que optarão pela docência } \\
\text { na escola pública, depois de formados. }\end{array}$ \\
\hline
\end{tabular}

Fonte: Os Autores (2016).

\subsection{Análise das respostas dos licenciandos}

Esta análise destaca mais informações obtidas no processo de pesquisa e alia importantes referenciais teóricos, com vistas a melhor elucidar as respostas recebidas.

Verificamos que, de um modo geral, os licenciandos apresentam uma avaliação muito positiva, e quase unânime, quanto à proposta e benefícios do PIBID e do Subprojeto Matemática em relação às experiências acadêmicas e profissionais; às diversas metodologias 
e didáticas observadas; ao contato com a realidade da escola pública; ao compartilhamento de experiências com as coordenadoras e supervisoras do programa, que promovem a reflexão sobre a teoria e a prática docente nos momentos dedicados às reuniões; bem como em relação à melhoria da qualidade da Educação - elementos efetivamente presentes e vivenciados durante a atuação no programa e subprojeto, conforme a percepção dos entrevistados.

É de fundamental importância, na opinião dos licenciandos, reunir o grupo de professores para a socialização de problemas, temas, matérias, intercâmbio de experiências e outros assuntos pertinentes ao universo da Educação e prática docente.

Observa-se que o Projeto PIBID busca romper paradigmas, ao propor as observações em sala de aula e o contato dos licenciandos com as mais diversas metodologias de ensino, de forma que possam refletir sobre a práxis, adquirir confiança e segurança para lecionar. A ideia de formar o professor, concomitante com a sua presença no cotidiano da escola, especialmente com o acompanhamento de um professor mais experiente, possibilita a reflexão sobre os fazeres pedagógicos em relação às teorias associadas a estes fazeres, constituindo-se como um verdadeiro exercício de aproximação entre a teoria e a prática, conforme pontua Nóvoa (2009) em relação à práxis docente e a formação continuada dos professores.

Em unanimidade, os entrevistados consideram que o PIBID tem efetivado melhorias na qualidade do ensino e, em especial, no ensino da Matemática, principalmente por meio de novas metodologias e didáticas, a exemplo dos jogos e materiais concretos, bem como tem aperfeiçoado o exercício da docência.

Em relação à motivação para a docência na escola pública, $81 \%$ dos entrevistados acreditam que irão optar pela docência na rede pública de ensino, depois de formados. Porém, em que pese a positividade desta afirmação, e que vai ao encontro ao objetivo do PIBID de incentivar os licenciandos à carreira docente, este indicador deve ser considerado no plano das "intenções futuras", pois é passível de confirmação somente após a formatura dos li- 
cenciandos e quando estes efetivamente adentrarem no mercado de trabalho da Educação, como professores. Para alguns licenciandos, a permanência na Educação pública apresenta-se apenas como temporária, ou como uma etapa transitória, até a possibilidade de se inserirem como professores na rede particular e/ou no Ensino Superior - a grande meta de muitos.

Nesse sentido, é importante destacarmos que é histórico o desencanto pela docência que atinge muitos professores, e que foi atribuído à democratização do ensino, às transformações sociais que aconteceram por volta dos anos de 1960, além de tantas outras razões que evoluíram até os dias atuais. Esta questão, segundo Gatti e Barreto (2009), que discutem com profundidade a temática, em um contexto educacional mais amplo, denota um alto grau de exigência em relação à formação e, mais, à formação continuada, embora as condições ofertadas aos profissionais não sejam atrativas, vistos os baixos salários, a precariedade e/ou ausência de recursos disponíveis em muitas escolas, à diminuta valorização e prestígio social da profissão. Tal condição, apesar das iniciativas e políticas instauradas, interfere sobremaneira na atratividade e escolha da profissão, principalmente se considerada a escassez de perspectivas futuras.

\section{Conclusão}

A pesquisa de campo desenvolvida com os licenciandos aponta, na percepção dos entrevistados, a validade do PIBID e de seus subprojetos, principalmente no sentido de contribuir para a melhoria da formação docente, do ensino em geral, do ensino específico da Matemática e da Educação Básica brasileira, pois o programa apresenta-se como uma importante iniciativa que viabiliza a reflexão, a conciliação e intercâmbio produtivo entre a teoria e a prática, as quais coexistem no espaço escolar e são experimentadas e vivenciadas pelos licenciandos e demais atores envolvidos no processo de ensino-aprendizagem.

Especificamente em relação à Matemática, essa possibilidade se efetiva à medida que o programa propicia, por meio da sua di- 
nâmica de trabalho, meios para que os professores compreendam a lógica e a mecânica pedagógica da construção do conhecimento, por meio do contato com diversas metodologias e ações pedagógicas pautadas em formas diferenciadas do ensino da Matemática.

A implantação de programas como o PIBID elevou a importância da formação continuada para os professores como uma prática primordial para o atendimento das novas demandas sociopolíticas, econômicas e culturais derivadas da globalização e do crescente desenvolvimento das tecnologias, em especial das tecnologias da informação e da comunicação, as quais transformaram o mundo e o país ao impactar diretamente a Educação e seus sistemas.

O PIBID destaca-se justamente neste sentido ao colocar o aspirante à docência no contexto prático do dia a dia das instituições escolares, com a finalidade de transmutar velhos paradigmas e ao instituir e promover novas metodologias de ensino, que estimulam e buscam renovar o sistema de ensino-aprendizagem com maior qualidade e de modo a romper com estruturas simplistas de reprodução de informações e que não constroem conhecimentos e saberes sólidos. Porém, mais do que isso, é preciso também que as condições de trabalho e, especialmente salariais, dos professores, conforme destaca Gatti e Barreto (2009), sofram uma significativa melhora para atrair mais profissionais para as escolas da rede pública de ensino.

\section{Referências}

CURI, Edda. Formação de professores de matemática: realidades presentes e perspectivas futuras. 2000. 244f. Dissertação (Mestrado em Ensino de Matemática) - Pontifícia Universidade Católica (PUC), São Paulo: 2000. Disponível em: <http://www.educadores.diaadia.pr.gov.br/arquivos/File/2010/artigos_teses/ MATEMATICA/Dissertacao_Eda.pdf>. Acesso em: 20 jan. 2014.

FERREIRA JR, Amarilio; BITTAR, Marisa. A ditadura militar e a proletarização dos professores. Revista Educação e Sociedade, Campinas, v. 27, n. 97, p. 11591179, set./dez. 2006. Disponível em: <http://www.cedes.unicamp.br>. Acesso em: 25 out. 2015 .

FIORENTINI, Dario. Alguns modos de ver e conceber o ensino da matemática 
no Brasil. Zetetike. n. 4, 3. p. 1-37. 1995. Campinas (SP).

GATTI, Bernardete A.; BARRETO, Elba Siqueira de Sá. Professores do Brasil: Impasses e desafios. Brasília (DF): UNESCO, 2009.

MIGUEL, Antonio; MIORIM, Maria Ângela. História na educação matemática: propostas e desafios. Belo Horizonte (MG): Autêntica, 2004.

MINAYO, Maria Cecília de Souza; SANCHES, Odécio. Quantitativo-qualitativo: oposição ou complementaridade? In: Caderno de Saúde Pública da Escola Nacional de Saúde Pública da Fiocruz. Rio de Janeiro, 9 (3): 239-262, jul/set, 1993. Disponível: <http://www.scielo.br/pdf/csp/v9n3/02.pdf>. Acesso em: 3 mar. 2015.

NÓVOA, António. Professores - imagens do futuro presente. Lisboa: Educa, 2009.

OLIVEIRA, João Ferreira; CATANI, Afrânio Mendes; SILVA-JUNIOR, João dos Reis (Org.) Educação superior no Brasil: em tempos de internacionalização. São Paulo: Xamã, 2010.

PIRES, Célia Maria Carolino. Currículos de matemática: da organização linear à idéia de rede. São Paulo: FTD, 2000.

RICHARDSON, Roberto Jarry. Pesquisa social: métodos e técnicas. São Paulo: Atlas, 1999.

SILVA, Paulo Sérgio Ribeiro da. Vivências curriculares na licenciatura em matemática no Cesp/Uea/Parintins. Dissertação (Mestrado em Ensino de Ciências na Amazônia) - Universidade do Estado do Amazonas, 2013. Disponível em: $<$ http://www.pos.uea.edu.br/data/area/titulado/download/36-19.pdf $>$. Acesso em: 25 out. 2015 .

YIN, Robert K. Estudo de caso: planejamento e métodos. 4 ed. Porto Alegre (RS): Bookmam, 2010.

\section{LEGISLAÇÃO [Relacionada por data de promulgação para facilitar a pesquisa]}

BRASIL. (1824). Constituição Politica do Império do Brasil de 1824. (Elaborada por um Conselho de Estado e outorgada pelo Imperador D. Pedro I, em 25 de março de 1824). Disponível em: < http://www.planalto.gov.br/ccivil_03/ constituicao/constituicao24.htm>. Acesso em: 14 mai. 2014. 
BRASIL. (1961). Lei n. 4.024, de 20 de dezembro de 1961. (Fixa as Diretrizes e Bases da Educação Nacional - Revogada pela Lei n. 9.394, de 1996, exceto os artigos $6^{\circ}$ a $9^{\circ}$ ). Presidência da República. Casa Civil. Subchefia para Assuntos Jurídicos. Diário da República Federativa do Brasil. Brasília (DF): DOU de 27 de dezembro de 1961. Disponível em: <http://www.planalto.gov.br/ccivil_03/leis/ 14024.htm>. Acesso em: 1 ago. 2014.

BRASIL. (1962). Parecer n. 292, de 14 de novembro de 1962. (Estabelece a parte pedagógica dos currículos mínimos relativos aos cursos de licenciatura). Ministério da Educação (MEC). Conselho Federal de Educação (CEF). Brasília (DF): MEC, Diário Oficial da União, 10 dez. 1962. p. 95-100; p. 216-218.

BRASIL. (1988). Constituição da República Federativa do Brasil de 1988. Presidência da República. Casa Civil. Subchefia para Assuntos Jurídicos. Disponível em: <ww.planalto.gov.br/ccivil_03/constituicao/constituicao.htm>. Acesso em: 14 mai. 2014.

BRASIL. (1996). Lei n. 9.394, de 20 de dezembro de 1996. (Fixa as Diretrizes e Bases da Educação Nacional). Presidência da República. Casa Civil. Subchefia para Assuntos Jurídicos. Disponível em: <http://www.planalto.gov.br/ccivil_03/ leis/19394.htm>; <http:// portal.mec.gov.br/arquivos/pdf/ldb.pdf>. Acesso em: 1 ago. 2014.

BRASIL. (2010). Decreto n. 7.219, de 24 de junho de 2010. (Dispõe sobre o Programa Institucional de Bolsa de Iniciação à Docência - PIBID e dá outras providências). Diário Oficial [da] República Federativa do Brasil, Brasília, DF, 25 jun. 2010. Disponível em: < http://www.planalto.gov.br/ccivil_03/_ato20072010/2010/decreto/d7219.htm>. Acesso em: 20 mai. 2014.

BRASIL. (2013). Lei n. 12.796, de 4 de abril de 2013. (Altera a Lei no 9.394, de 20 de dezembro de 1996, que estabelece as diretrizes e bases da educação nacional, para dispor sobre a formação dos profissionais da educação e dar outras providências). Presidência da República. Casa Civil. Subchefia para Assuntos Jurídicos. Disponível em:<http://www.planalto.gov.br/ccivil_03/_ato2011-2014/2013/ lei/112796.htm>. Acesso em: 1 ago. 2014.

BRASIL. (2015). Programa institucional de bolsas de iniciação à docência (PIBID). Ministério da Educação. Disponível em: <http://portal.mec,gov.br/index>; <http://www.capes.gov.br/educacao-basica/capespibid>; <http://www.capes.gov. br/educacao-basica/capespibid/pibid-diversidade>. Acesso em: 5 abr. 2015. 
Marcelo Furlin - Universidade Metodista de São Paulo - Escola de Comunicação, Educação e Humanidades. Rua do Sacramento, 230 - 09640-000 - Rudge Ramos, São Bernardo do Campo (SP), telefone (11) 4366-5000. Endereço eletrônico: marcelo.furlin@metodista.br

Silvana Pucetti - Universidade Metodista de São Paulo - Escola de Comunicação, Educação e Humanidades. Rua do Sacramento, 230 - 09640-000 - Rudge Ramos, São Bernardo do Campo (SP), telefone (11) 4366-5000. Endereço eletrônico: silvanapucetti@gmail.com 